\title{
Magnetic resonance imaging of coronary arteries: technique and preliminary results
}

\author{
D J Pennell, J Keegan, D N Firmin, P D Gatehouse, S R Underwood, D B Longmore
}

Magnetic Resonance Unit, Royal Brompton National Heart and Lung Hospital, London

D J Pennell

J Keegan

D N Firmin

P D Gatehouse

$S$ R Underwood

D B Longmore

Correspondence to:

Dr D J Pennell, Magnetic

Resonance Unit, Royal

Brompton National Heart Brompton National Heart and Lung Hospital, Syndey

Accepted for publication 16 June 1993

\begin{abstract}
Background-Coronary artery imaging is an important investigation for the management of coronary artery disease. The only reliable technique presently available, $x$ ray contrast angiography, is invasive and is associated with a small morbidity and mortality. Alternative non-invasive imaging would be useful, but the small calibre and tortuosity of the coronary vessels, and cardiac and respiratory motion create formidable imaging problems.
\end{abstract}

Objective-The development of rapid magnetic resonance imaging of the coronary arteries.

Patients-21 healthy controls and five patients with coronary artery disease established by $x$ ray contrast angiography, of whom two had undergone bypass grafting.

Methods-Magnetic resonance imaging was performed with gradient echoes and a segmented k-space technique, such that a complete image was acquired in $\mathbf{1 6}$ cardiac cycles during a breathhold. The signal from fat was suppressed and images were acquired in late diastole to reduce artefact from cardiac motion. An imaging strategy was developed for the proximal arteries, including longitudinal imaging from oblique planes defined according to the origins and the continuation of the arteries in the atrioventricular grooves or interventricular sulcus.

Results-Of the 26 subjects studied, 22 were imaged successfully. Identification of the artery was possible for the left main stem, left anterior descending, right coronary, and left circumflex arteries respectively in $95 \%, 91 \%, 95 \%$, and $76 \%$. The arterial diameter at the origin could be measured in $77 \%, 77 \%, 81 \%$, and $63 \%$. The mean (SD) arterial diameter in each case $(4.8(0.8), 3.7(0.5), 3.9$ $(0.9)$, and $2.9(0.6) \mathrm{mm})$ was not significantly different from reference values. The mean length of artery visualised was $10.4(5 \cdot 2), 46 \cdot 7(22 \cdot 8), 53.7(27 \cdot 9)$, and $26.3(17 \cdot 5) \mathrm{mm}$. In 12 healthy men the total coronary area was $30.9(9.2) \mathrm{mm}^{2}$ and the ratio compared with body surface area was $16 \cdot 4(4 \cdot 4) \mathrm{mm}^{2} \mathrm{~m}^{-2}$ (both $\mathbf{p}=$ NS compared with reference values). In seven patients in whom $x$ ray contrast coronary angiography was available, the proximal arterial diameter was $3.9(1 \cdot 1)$ mm measured by magnetic resonance and $3.7(1 \cdot 0) \mathrm{mm}$ by $x$ ray contrast angiography $(p=N S)$. The mean difference between the measurements was 0.2 $(0.5) \mathrm{mm}$, and the coefficient of variation was $13 \cdot 7 \%$. All five occluded coronary arteries were identified, as were all three vein grafts. In two patients insertion of the graft into the native arteries was identified.

Conclusions-Magnetic resonance coronary angiography is feasible. Good results were obtained by a breath-hold, fat suppression technique, gated to late diastole. Arterial occlusions and vein grafts were readily identified. Further studies are required to establish its value in the detection of coronary stenosis and to develop the measurement of coronary flow velocity which could be used to quantify the severity of the stenosis.

(Br Heart f 1993;70:315-326)

Imaging of the coronary arteries has been one of the most important medical advances in the management of coronary artery disease. $x$ Ray contrast angiography requires arterial catheterisation and carries a small risk of death and other complications. ${ }^{12}$ At present there is no satisfactory alternative. Though $x$ ray contrast coronary angiography provides little information on coronary flow or the vessel wall, it is an essential examination before revascularisation by coronary bypass surgery or angioplasty.

Magnetic resonance angiography has progressed in recent years, challenging conventional angiography for the carotid ${ }^{3}$ and renal ${ }^{4}$ vessels and proving to be superior to the conventional technique for peripheral angiography. ${ }^{5}$ However, magnetic resonance angiography of the coronary vessels has been hindered by a combination of formidable problems. These include their small calibre, cardiac motion, respiratory motion, tortuosity, and proximity to other tissues of high water density. None of these problems, however, is insurmountable, and images of the coronary arteries ${ }^{67}$ and coronary artery bypass grafts $^{89}$ were first acquired by standard MR techniques several years ago (fig 1), but the technique was unreliable and the resolution was limited because of the long imaging times. Technological advances have now made fast imaging possible with single image acquisition times as low as $10 \mathrm{~ms}$ by the 


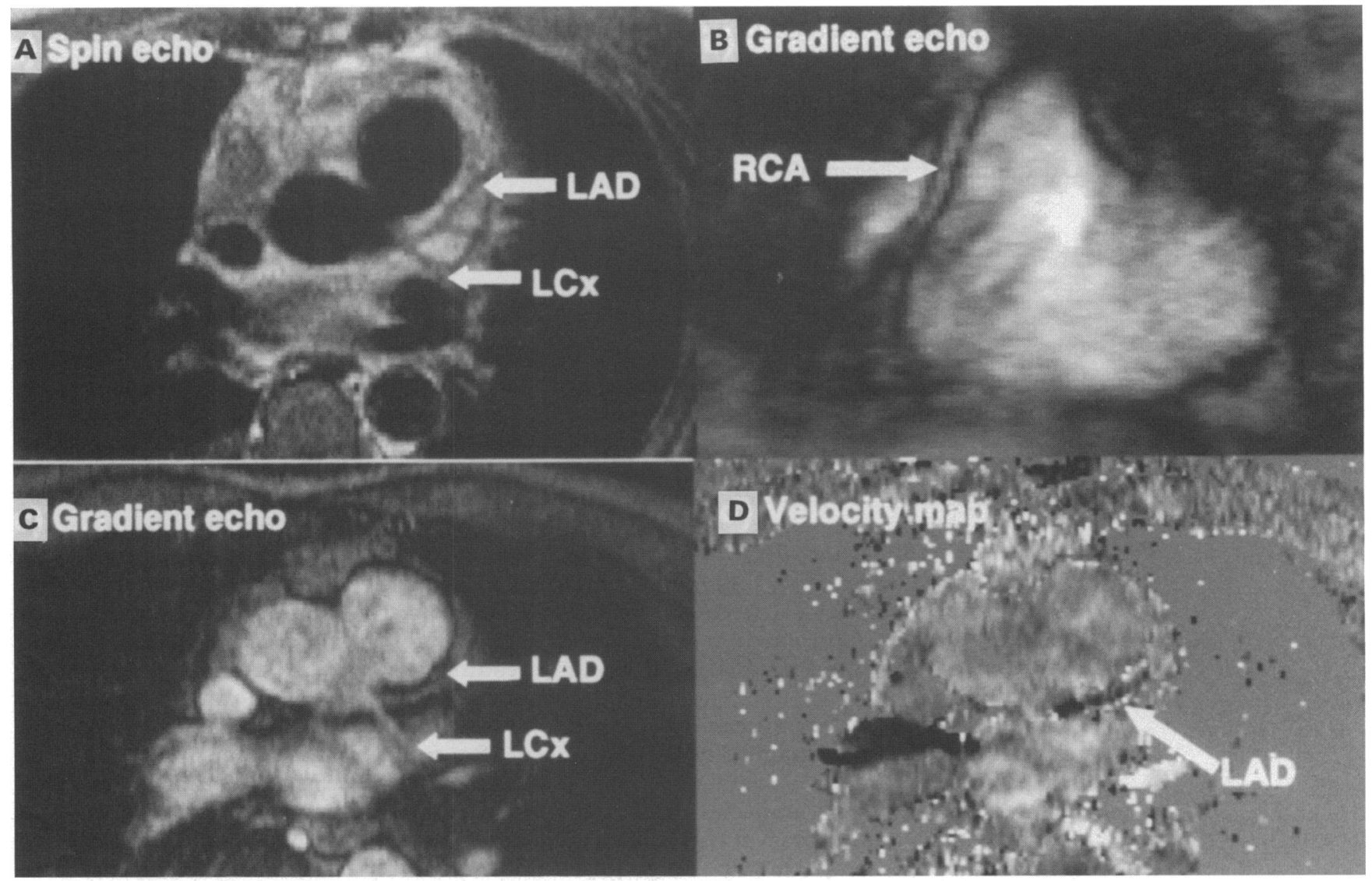

Figure 1 Magnetic resonance coronary artery imaging with conventional techniques developed between 1986 and 1989. (A) Spin echo image in the transaxial plane. The left main and branches are seen with low signal intensity. (B) Conventional gradient echo image in an oblique sagittal plane showing the right coronary artery in longitudinal section with high signal. (C) Conventional gradient echo image showing the left main stem and branches in the transaxial plane, which was used in (D) for velocity mapping to show measurements of velocity (in black) in the left anterior descending artery. $L A D$, left anterior descending artery; LCX; left circumflex artery; RCA; right coronary artery.

echo-planar technique, ${ }^{10} 300 \mathrm{~ms}$ using the fast low angle shot (FLASH) technique, ${ }^{11}$ and the possibility of magnetic resonance fluoroscopy at $12 \cdot 5$ frames per second. ${ }^{12}$ Recent studies suggest that such fast imaging techniques alleviate the above problems. ${ }^{13} 14 \mathrm{We}$ report our experience of fast gradient echo imaging of the coronary arteries.

\section{Patients and methods}

MAGNETIC RESONANCE IMAGING TECHNIQUE Magnetic resonance imaging was performed with a velocity compensated gradient echo sequence (TE $6.5 \mathrm{~ms}$, TR $15.7 \mathrm{~ms}$ ) and a segmented k-space technique, such that 8 phase encoding steps were acquired in each cardiac cycle. Images of $128 \times 256$ matrix were acquired over 16 cardiac cycles during breath-holding. The acquisition window for the 8 phase encoding steps was $126 \mathrm{~ms}$. It was positioned in mid to late diastole, during the period of minimal cardiac motion. Because of the high signal from fat which surrounds the coronary arteries, fat signal suppression was employed, with frequency selective pre-excitation and dephasing before water excitation. This technique relies on the phenomenon of chemical shift, whereby protons in fat precess at higher frequency than those in water because of their chemical environment. Studies were performed with a 1.5
T system (Picker International Vista scanner, Cleveland Heights, Ohio, USA), with a 60 $\mathrm{cm}$ patient bore. The field of view used was $20 \mathrm{~cm}$ and the slice thickness $4 \mathrm{~mm}$, giving an in-plane pixel size of $1.6 \times 0.8 \mathrm{~mm}$. The images were interpolated to $512 \times 512$ for display. In preparation for this study we performed imaging using the standard body coil and compared prone and supine imaging. We used the supine position in all subjects in this study because it was more comfortable. The body coil was used for the first seven subjects, but subsequently we used a lumbar spine surface coil over the anterior chest. Imaging took about an hour.

\section{CHARACTERISTICS OF SUBJECTS}

We studied 26 subjects (22 men, four women; mean (SD) age 49 (16) years). Their mean height was $174(9.8) \mathrm{cm}$, mean weight 73 (11) $\mathrm{kg}$, and mean body surface area 1.87 $(0 \cdot 19) \mathrm{m}^{2}$. Seven had undergone previous $x$ ray contrast coronary angiography, which showed normal coronaries in two and an isolated occluded left anterior descending artery in three. Coronary artery saphenous vein bypass grafting had been performed in two (one with occluded right coronary and left anterior descending arteries both bypassed, and one with an occluded right coronary artery with grafts to the distal right coronary artery and an obtuse marginal). 
IMAGING PLANES USED TO IDENTIFY THE CORONARY VESSELS

After careful shimming for fat suppression, coronal imaging was used to identify the coronary sinuses (fig 2). Transaxial or tilted transaxial images at the level of the sinuses were acquired to show the origins of the coronary arteries (fig 3). Contiguous overlapping slices were then acquired in the orthogonal or slightly oblique transaxial plane to show the course of the proximal right coronary artery passing between the pulmonary artery and the right atrium before its descent inferiorly (fig 4A-D).

Longitudinal imaging of the arteries was then performed. Multiple contiguous oblique slices with a $2 \mathrm{~mm}$ overlap were used to ensure complete imaging of the length of the artery as it passed in and out of the plane. The right coronary artery was identified in its

Figure 2 Fast gradient echo technique. Coronal images of the coronary sinuses showing the coronary origins $(A)$, the left main stem, and (B) the right coronary artery.
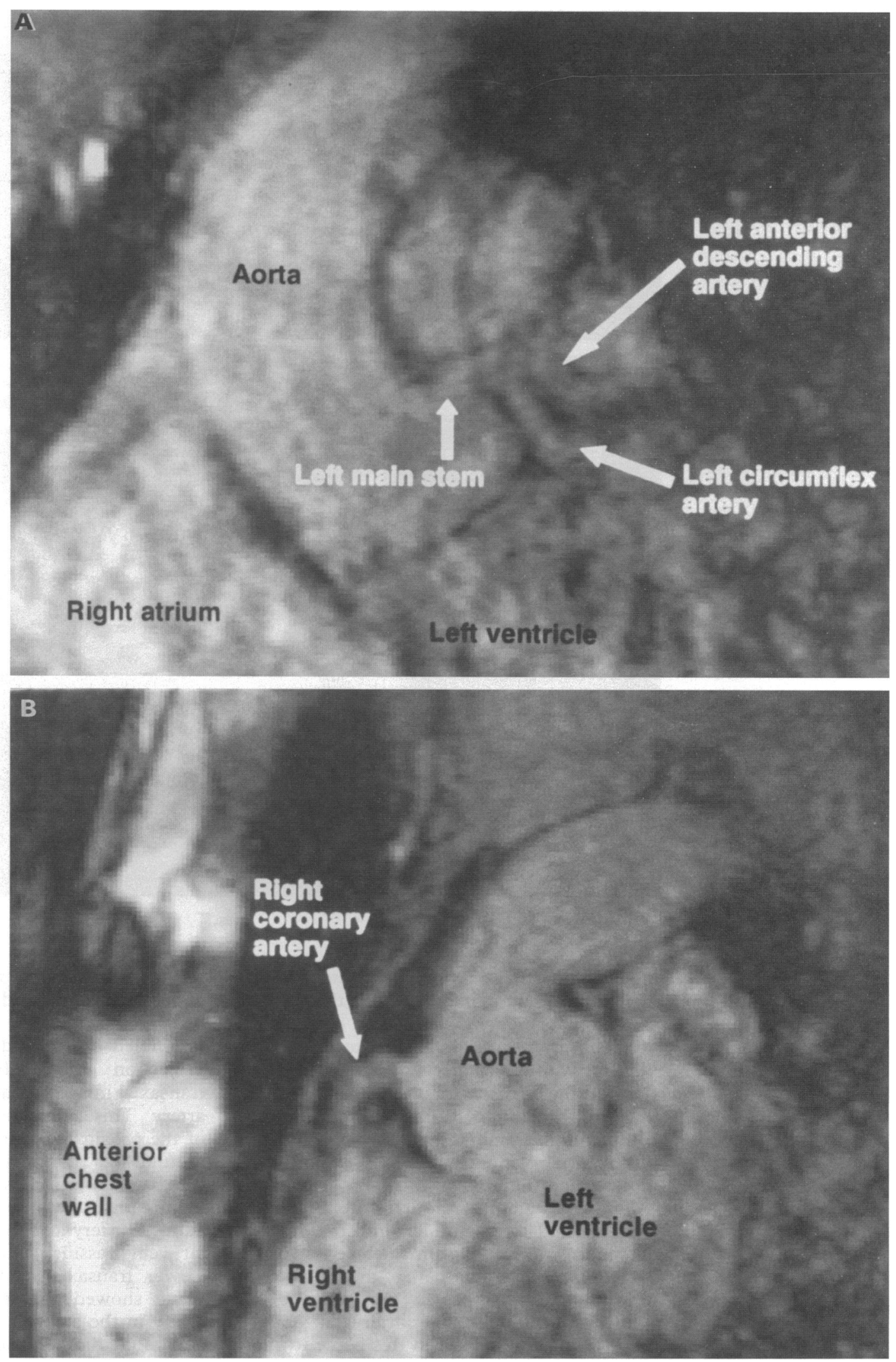
Figure 3 Fast gradient echo technique. Pair of transaxial images showing (A) the origin of the left main stem, the great cardiac vein, and a cross section of the right coronary artery; and (B) the origin of the right coronary artery with a portion of the proximal left anterior descending artery.
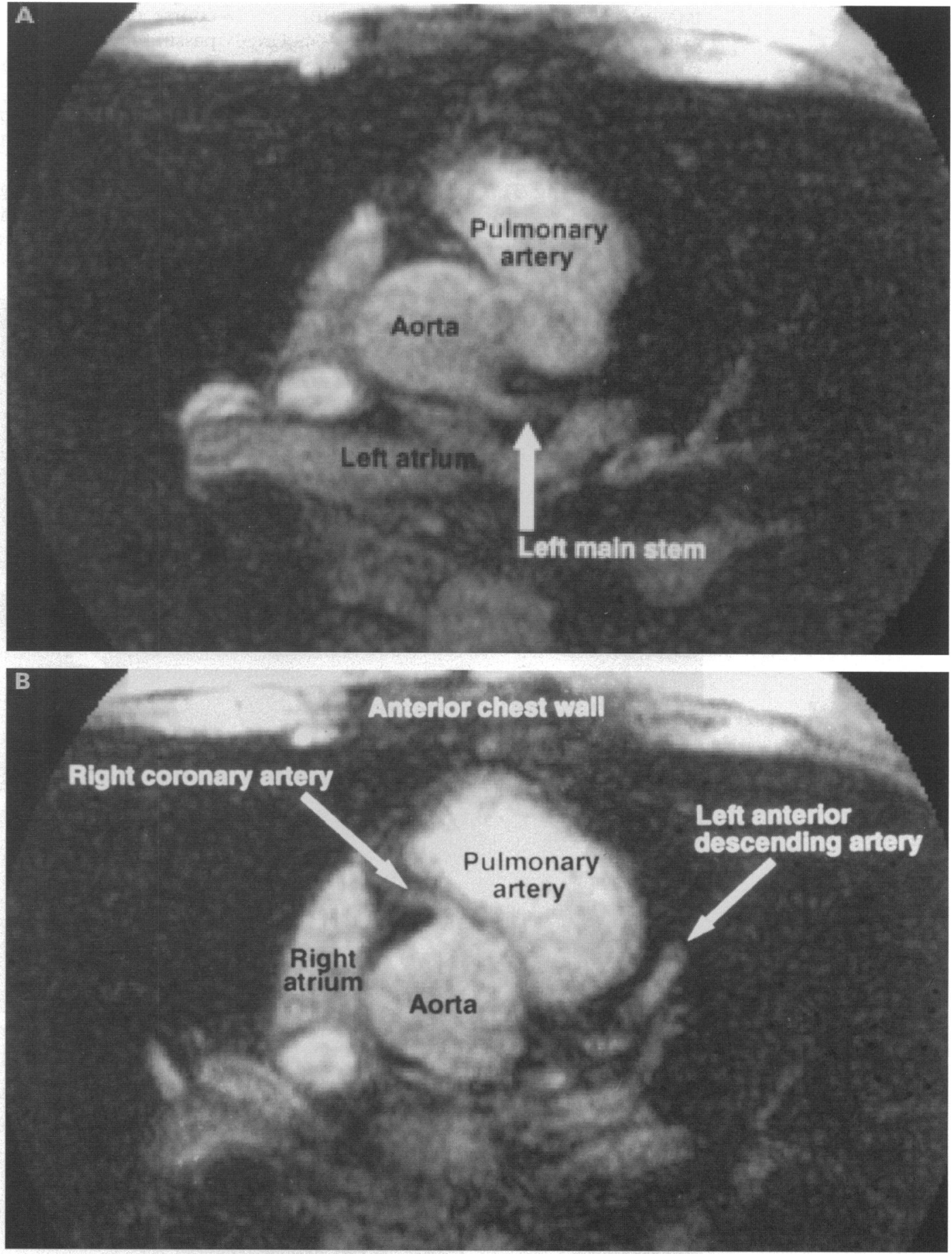

course along the anterior (right) atrioventricular groove by transaxial imaging through the ventricles. Longitudinal imaging of the right coronary artery was performed using oblique planes passing through its origin and its position in the atrioventricular groove (fig 5). When the tortuosity of the artery prevented complete imaging in this plane (fig $6 \mathrm{~A}$ ), a further oblique plane was acquired to image the mid-portion (fig 6B).

The main stem of the left coronary artery was followed to its division into left anterior descending and left circumflex arteries (fig 7). The course of the first part of the left anterior descending artery passed between the left atrium and the pulmonary artery. An oblique coronal image was used in this plane to show the proximal artery, the division of the left circumflex artery, and the downward inclination of this portion. This gave images that resembled a standard right anterior oblique projection (fig 8). From this, an oblique transaxial image was acquired of the proximal artery. This better showed the continuation of the proximal portion of the artery passing around the pulmonary artery and included the diagonal branches (fig 9). Also often seen in this plane was the division of the left circumflex artery and the anterior interventricular vein passing to the great cardiac vein. Lower transaxial imaging in the transaxial plane showed the left anterior descending artery in the anterior interventricular groove, and longitudinal oblique imaging again 


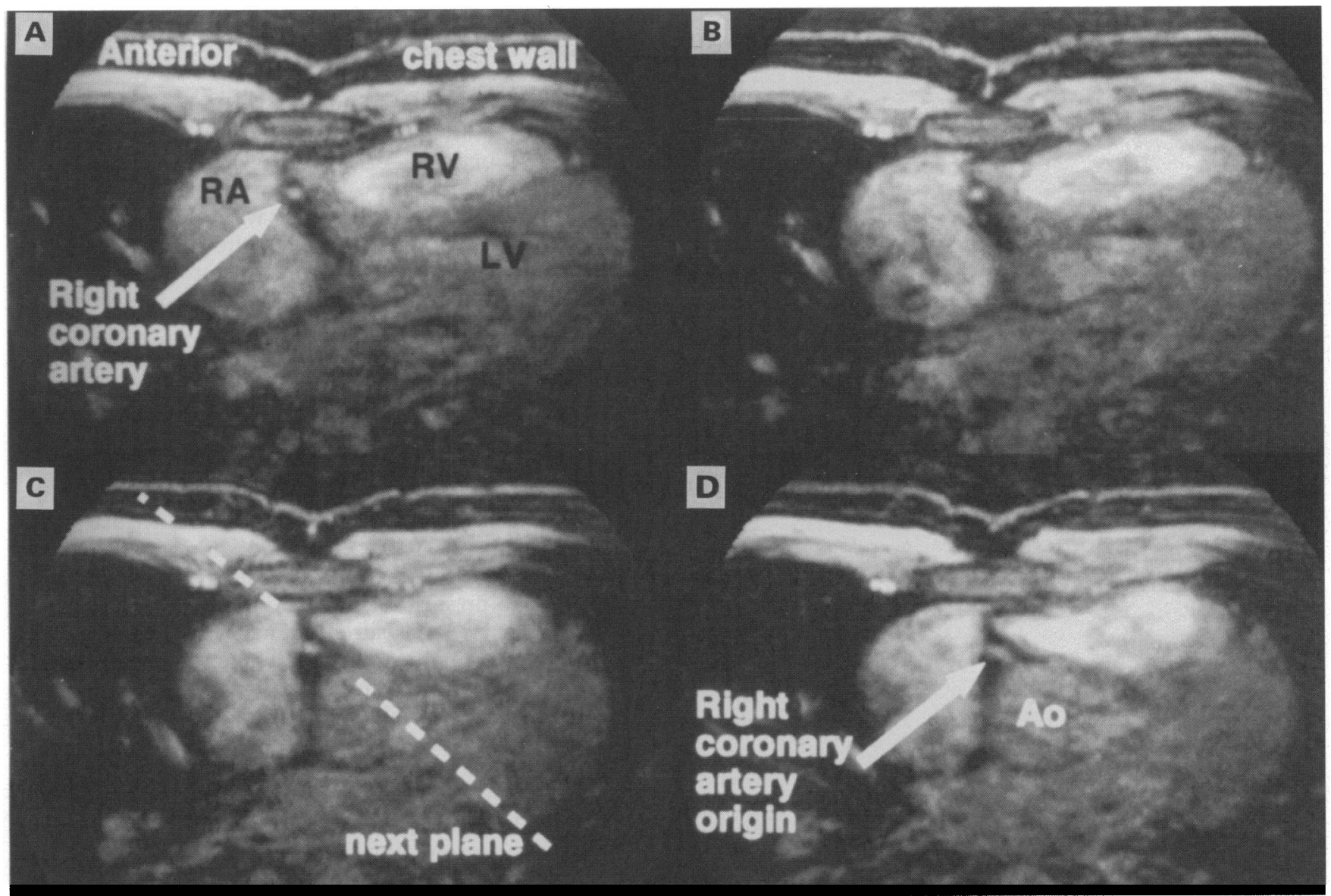

Figure 4 Fast gradient echo technique. Four contiguous overlapping transaxial slices showing the right coronary artery in the atrioventricular groove $(A, B, C)$ ascending to its origin $(D)$. The plane used for fig 5 is indicated in image $C$. Note the low signal from fat in all the images, produced by the fat signal suppression (between the skin and the anterior wall musculature). $R A$, right atrium; $R V$, right ventricle; $L V$, left ventricle; Ao, aorta.

showed the more distal artery. Further imaging of the left circumflex artery was performed by oblique imaging defined from the arterial origin and its continuation in the left (posterior) atrioventricular groove (fig 10).

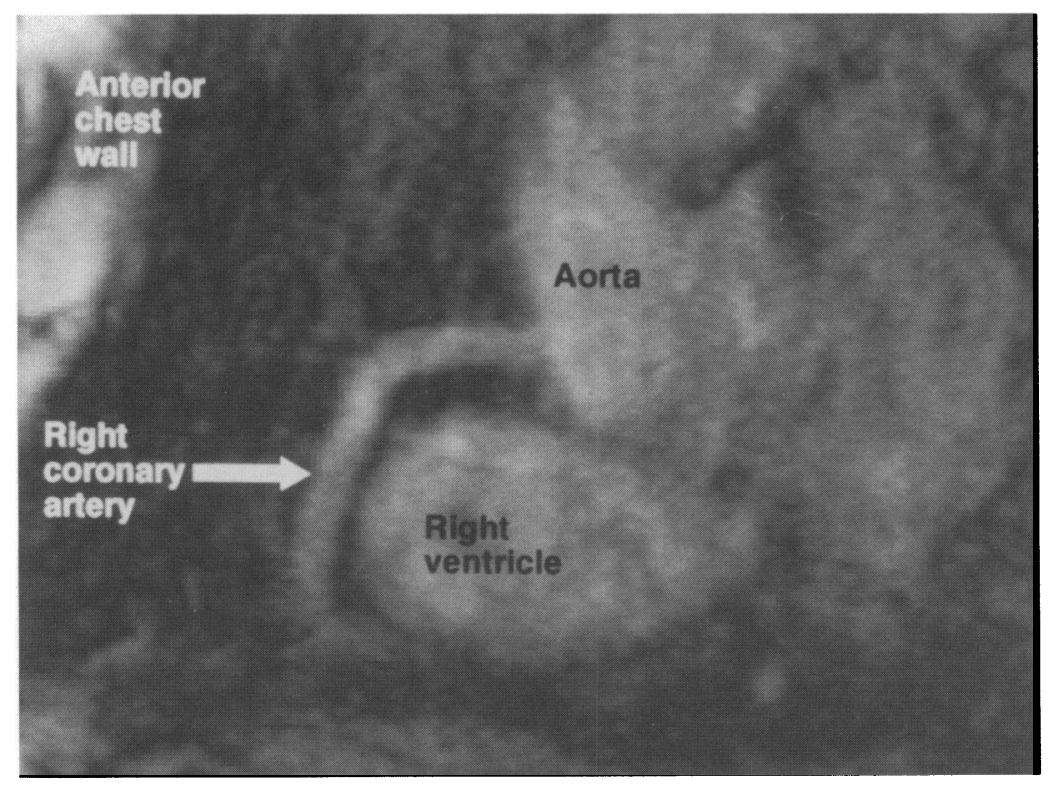

Figure 5 Fast gradient echo technique. Longitudinal image of the right coronary artery in an oblique sagittal plane as defined in fig $4 C$ (similar to the left anterior oblique projection of $X$ ray contrast angiography).
ANALYSIS OF MAGNETIC RESONANCE IMAGES

All images were reviewed by two experienced observers who had undertaken each examination. The identification of the individual arteries was agreed by consensus. The diameter and length of each artery were measured independently by both observers using onscreen cursors. The mean of these values was taken for subsequent analysis. An analysis of interobserver variability for the measurement of the diameter of each artery was also performed.

ANALYSIS OF CORONARY ANGIOGRAMS

Each of the seven angiograms was reviewed by an experienced observer blinded to the results of the magnetic resonance angiography, and measurements were made of the proximal arteries at their origins. The arterial diameter was calculated from the known width of the $7 \mathrm{~F}(2.3 \mathrm{~mm}$ diameter $)$ catheter on the film.

\section{STATISTICAL ANALYSIS}

All results are expressed as mean (1 SD). Interobserver variability was calculated by the coefficient of variation. ${ }^{15}$ Differences in the arterial diameter between magnetic resonance and $x$ ray contrast angiography were compared in the same way. Differences between the magnetic resonance and reference results for arterial measurements were compared by the unpaired $t$ test. 

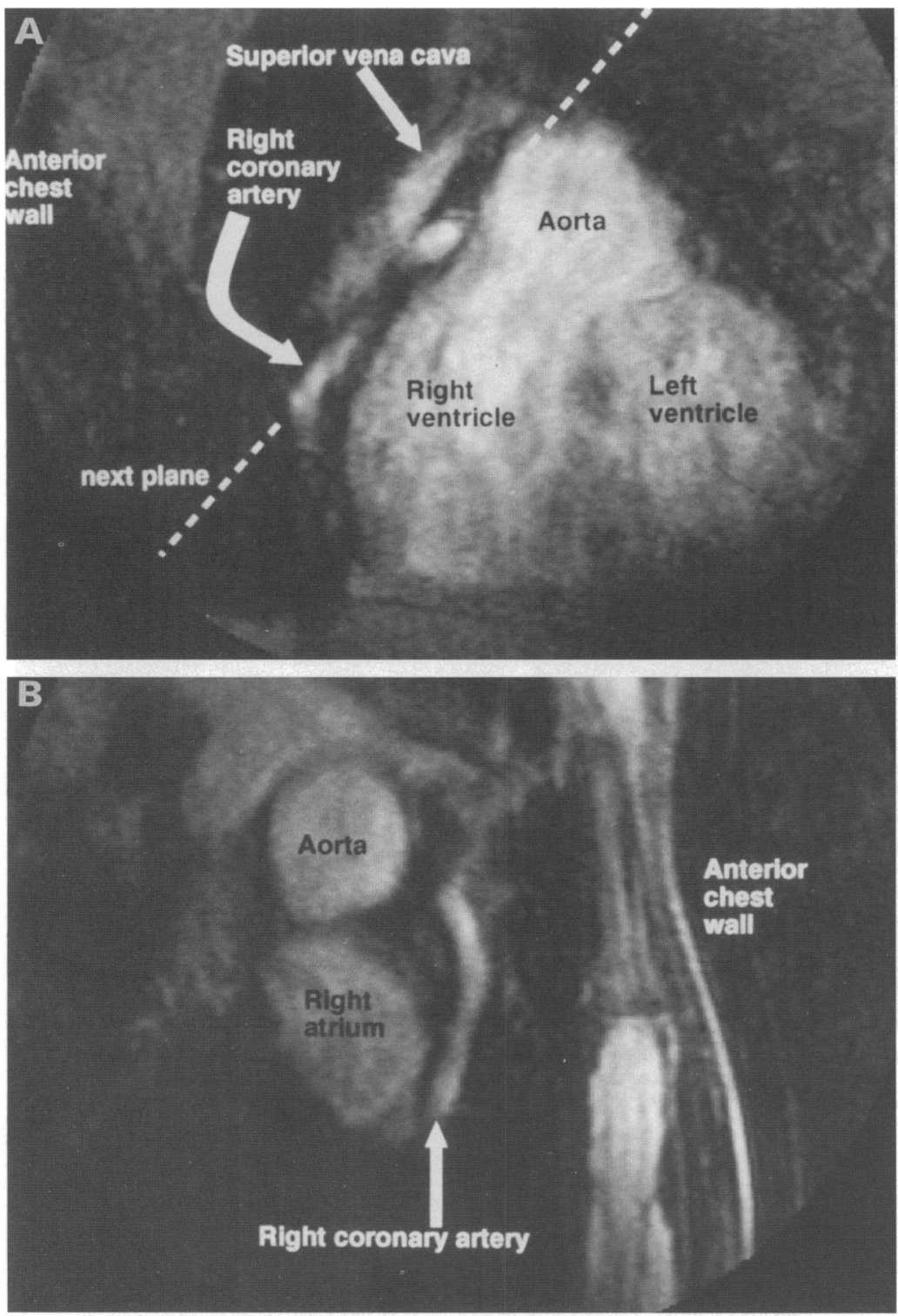

Figure 6 Fast gradient echo technique. (A) Longitudinal image of the right coronary artery showing its passage in and out of an oblique sagittal plane. The plane used for image $B$ is indicated. (B) Despite the tortuosity the entire length of this portion of the proximal right coronary artery can now be seen.

\section{Results}

MAGNETIC RESONANCE CORONARY

ANGIOGRAPHY

Experience with these techniques developed rapidly over examination of the first patients: four of the early studies were unsuccessful in imaging the coronary arteries. This was because of difficulties with shimming for fat suppression (2), coil malfunction (1), and a subject unable to cooperate with breathholding (1). The following results relate to the remaining 22 studies.

Table 1 shows the results of the identification and measurement of the coronary arteries. The left main stem (95\%), left anterior descending $(91 \%)$, and right coronary arteries (95\%) were identified in nearly all subjects, but identification of the the left circumflex artery was more difficult (76\%). Most of the missed arteries occurred early in our experience, but the left circumflex artery continued to pose problems. The mean diameter of the arteries measured by magnetic resonance was not significantly different from reference values from quantitative $x$ ray coronary angiography $^{16}$ (table 2). The length of the left main stem was $10.4 \mathrm{~mm}$ and ranged from 3.6 to $20.2 \mathrm{~mm}$, which is similar to the reference range. ${ }^{17}$ The mean length of artery seen by longitudinal imaging was greatest for the right coronary $(53 \mathrm{~mm})$ and left anterior descending arteries $(46 \mathrm{~mm})$, and least for the left circumflex artery $(26 \mathrm{~mm})$. The diagonal arteries were seen in five of the last nine subjects, when tilted transaxial imaging of the proximal left anterior descending artery was used, as described above. In 12 healthy men, the total coronary area, defined as the sum of the areas of the proximal arteries, ${ }^{18}$ was $30.9(9.2) \mathrm{mm}^{2}$ (range 19.4-57.2), and the total coronary area to body surface area ratio was 16.4 (4.4) $\mathrm{mm}^{2} \mathrm{~m}^{-2}$ (range 10.9-27.9). Neither measurement was significantly different from reference values. ${ }^{1618}$ The inter-
Figure 7 Transaxial image (fast gradient echo technique) showing the left main stem dividing into left anterior descending and left circumflex arteries. The plane used for fig 8 is indicated. Note the internal mammary arteries.

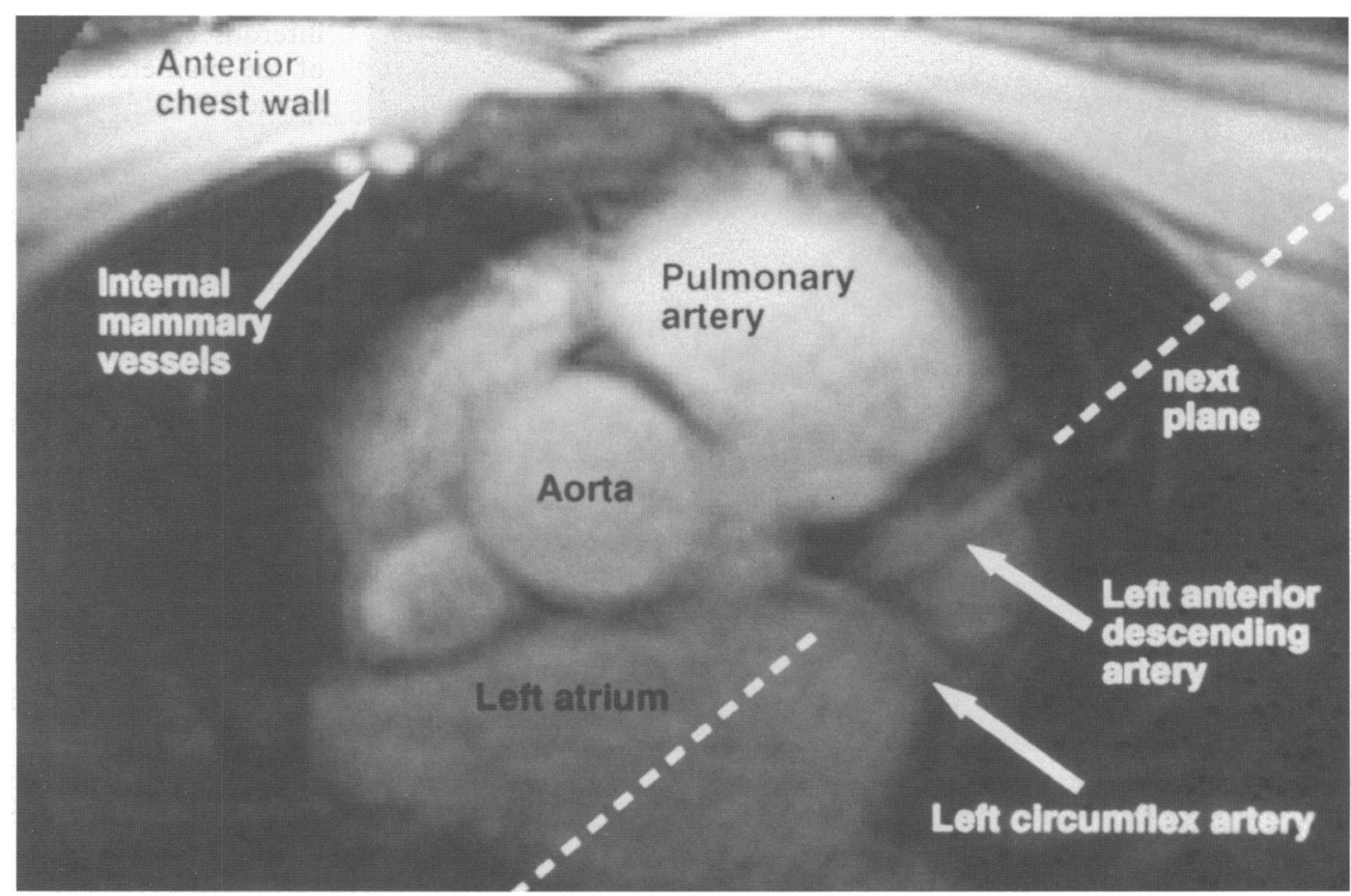


Figure 8 Longitudinal image (fast gradient echo technique) of the proximal left anterior descending artery. in an oblique sagittal plane (defined in fig 7) (similar to the right anterior oblique projection of $x$ ray contrast angiography). This inclivies the origin of the left circumflex artery. The plane used for fig 9 is indicated.

Figure 9 Longitudinal image (fast gradient echo technique) of the proximal left anterior descending artery and a diagonal branch in an oblique transaxial plane orientated to the left, as defined in fig 8 .
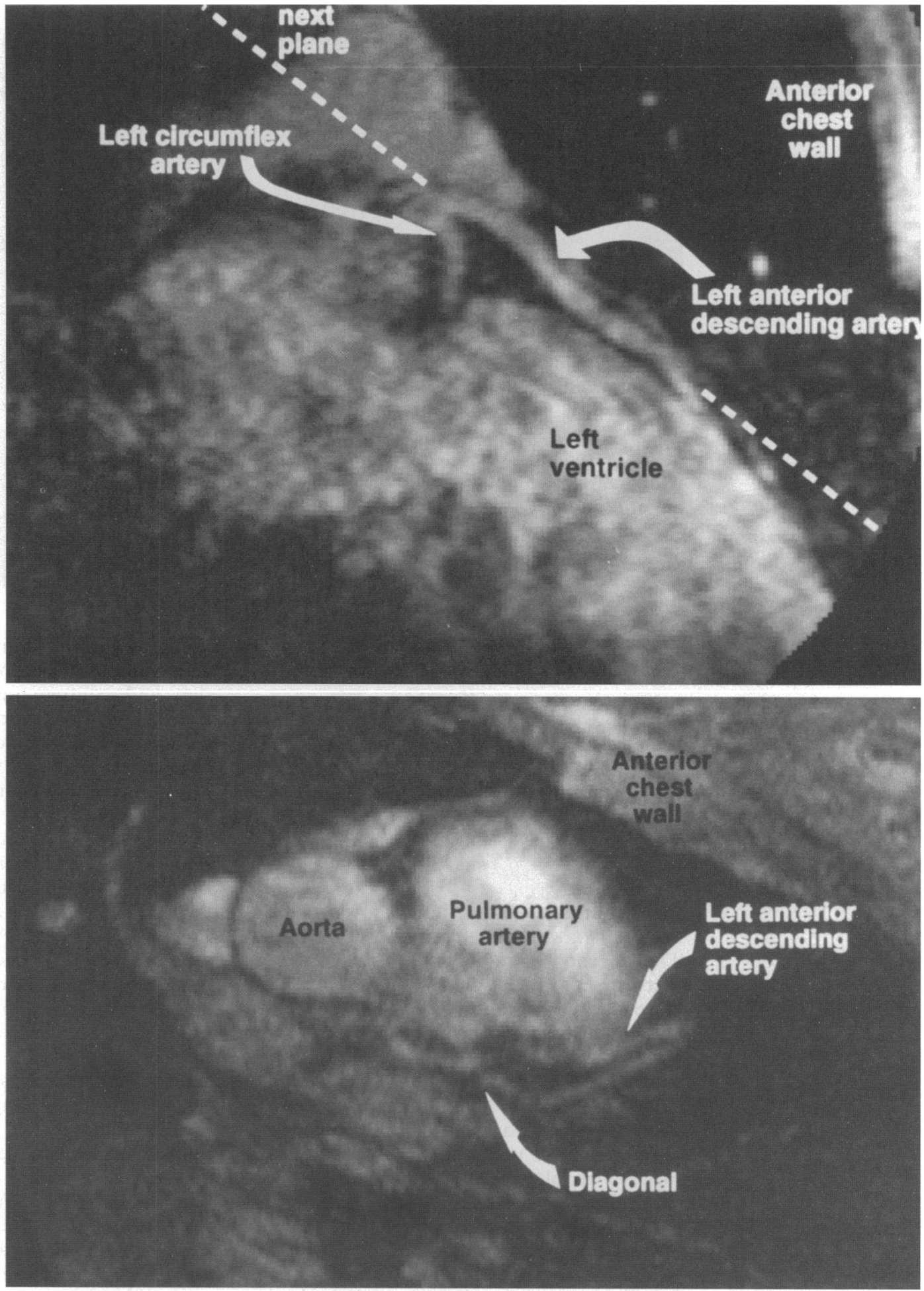

observer variation for measurement of the diameter of the proximal arteries was $7 \%$ for the left main stem, $12 \%$ for the left anterior descending artery, $11 \%$ for the right coronary artery, and $18 \%$ for the left circumflex artery.

COMPARISON OF MAGNETIC RESONANCE AND $X$ RAY CONTRAST CORONARY ANGIOGRAPHY The proximal arterial diameter measured by magnetic resonance was $3.9(1.1) \mathrm{mm}$, and by $x$ ray contrast angiography $3.7(1.0) \mathrm{mm}$ $(\mathrm{p}=\mathrm{NS})$. The mean difference between the measurements was $0.2(0.5) \mathrm{mm}$ and the coefficient of variation was $13 \cdot 7 \%$. Coronary artery disease was present in five of the seven patients with previous $x$ ray contrast angiography. The occluded left anterior descending artery was identified in all four patients and there was clear similarity between the magnetic resonance and conventional coronary images (fig 11A and B). The insertion of the bypass graft distal to the left anterior descending artery occlusion was identified and compared with conventional angiography (fig 12A and B). In one patient, right coronary artery occlusion was identified, and vein grafts to the right coronary and left circumflex arteries visualised (fig 13). 
Figure 10 Longitudinal image (fast gradient echo technique) of the left circumflex artery in an oblique sagittal plane.

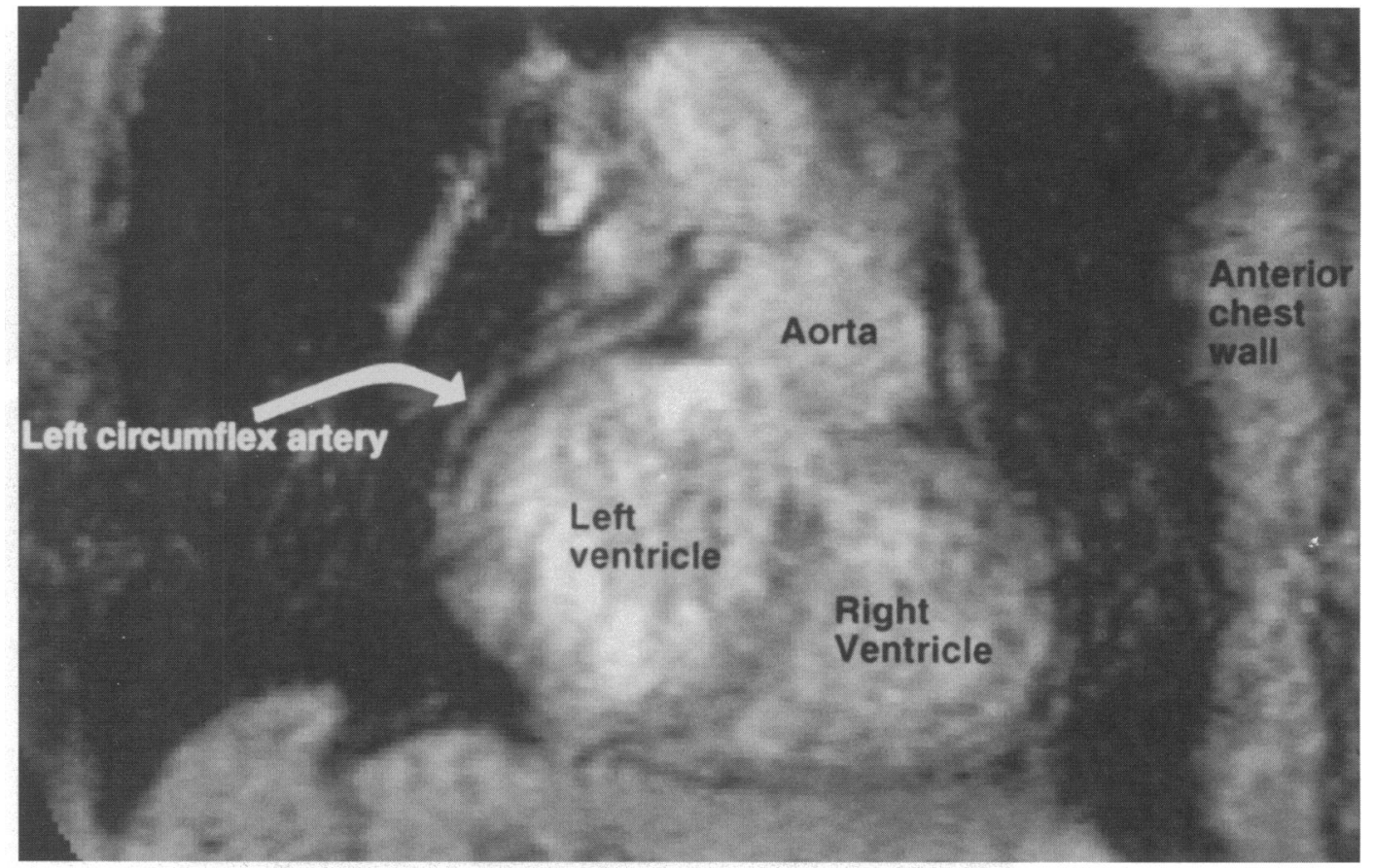

Table 1 Results of magnetic resonance coronary angiography in 22 subjects (percentages given in parentheses)

\begin{tabular}{lllll}
\hline & $L M S$ & $L A D$ & $R C A$ & $L C x$ \\
\hline Identified & $21(95)$ & $20(91)$ & $21(95)$ & $16(76)$ \\
Measurements possible in: & $17(77)$ & $17(77)$ & $18(81)$ & $14(63)$
\end{tabular}

LMS = left main stem; LAD; left anterior descending artery; RCA; right coronary artery; LCx; left circumflex artery.

\section{Discussion}

DEVELOPMENT OF X RAY CONTRAST

CORONARY ANGIOGRAPHY AND ALTERNATIVES

The insertion of catheters into the heart was first practised in 1929 by Forssman. ${ }^{19}$ Coronary angiography has been developed and practised for the diagnosis of coronary artery disease over the past 35 years, first using aortic root flushes, ${ }^{20}$ and later, selective catheterisation of the individual arteries. ${ }^{21-23}$ The modern technique typically involves a hospital stay of up to 24 hours, local anaesthesia, arterial puncture or incision, the passage of arterial catheters, the injection of radio-opaque $x$ ray contrast marterial, and the exposure of the patient and immediate staff to $x$ rays. A satisfactory and less invasive alternative to this procedure has not been forthcoming despite progress in imaging of the proximal arteries by echocardiography. ${ }^{24}$ and quantification of coronary artery calcification by ultrasfast computed $x$ ray tomography. ${ }^{25}$ Magnetic resonance imaging is a new technique for coronary artery imaging. It has many attractive properties for the investigation of coronary artery disease, which include its non-invasive nature, full oblique imaging capability, and freedom from ionising radiation and contrast injections. The development of satisfactory coronary artery imaging with this technique would therefore represent a substantial advance for clinical management of patients with known or suspected coronary artery disease.

Magnetic resonance imaging of the in-vivo human heart has been in development since the first gated cardiac images were acquired between 1978 and 1983 and reported by Steiner $e t a l^{26}$ and Alfidi et $a l^{27}$ Coronary artery imaging has been hindered by the long imaging times, which allows respiratory and aperiodic cardiac motion to introduce artefact. Spin echo or gradient echo imaging of the coronary arteries were occasionally successful, but no robust technique was developed (fig 1). ${ }^{672829}$ Rapid imaging techniques such as echo planar imaging, ${ }^{30}$ and breathhold imaging using selective inversion recovery, ${ }^{31}$ or fast gradient echo imaging, ${ }^{13}{ }^{14}$ have been more reliable. Fast gradient echo imaging is slower than the echo-planar technique, but the raw data are acquired during a breath-hold, thereby eliminating an important cause of artefact. If the segments are also acquired during mid to late diastole, artefact from cardiac motion is reduced. The remaining technical problems include the tortuosity of the vessels and their small size. These problems can be countered by use of surface coils, thin slices, a small field of view and multiple overlapping contiguous slices in oblique planes containing the longitudinal

Table 2 Measurements made in 18 men: comparison with reference ranges

\begin{tabular}{|c|c|c|c|c|c|c|c|c|}
\hline & $L M S$ & Reference $e^{1617}$ & $L A D$ & Reference $e^{1617}$ & $R C A$ & Reference $^{1617}$ & $L C x$ & Reference $e^{1617}$ \\
\hline $\begin{array}{l}\text { Mean diameter mm (SD) } \\
\text { Mean length } \mathrm{mm}(\mathrm{SD}) \\
\text { range }\end{array}$ & $\begin{array}{l}4 \cdot 8(0 \cdot 8) \\
10 \cdot 4(5 \cdot 2) \\
3 \cdot 6-20 \cdot 2\end{array}$ & $\begin{array}{l}4.5(0.5) \\
5-20\end{array}$ & $\begin{array}{l}3 \cdot 7(0 \cdot 5) \\
46 \cdot 7(22 \cdot 8) \\
14-93 \cdot 8\end{array}$ & $\begin{array}{l}3.6(0.5) \\
-\end{array}$ & $\begin{array}{l}3.9(0.9) \\
53 \cdot 7(27 \cdot 9) \\
10 \cdot 8-118\end{array}$ & $\begin{array}{l}3.9(0.6) \\
-\end{array}$ & $\begin{array}{c}2 \cdot 9(0 \cdot 6) \\
26 \cdot 3(17 \cdot 5) \\
4 \cdot 5-63\end{array}$ & $\begin{array}{l}3.4(0.5) \\
-\end{array}$ \\
\hline
\end{tabular}

There were no significant differences between the diameters measured by magnetic resonance and the reference measurements.

See footnote to table 1 for abbreviations. 
Figure 11 (A) Fast gradient echo technique MR image showing occluded left anterior descending artery in the same plane as fig 8.

(B) Conventional $x$ ray contrast angiogram of the same artery in the right anterior oblique projection. Note the similarity in appearances.
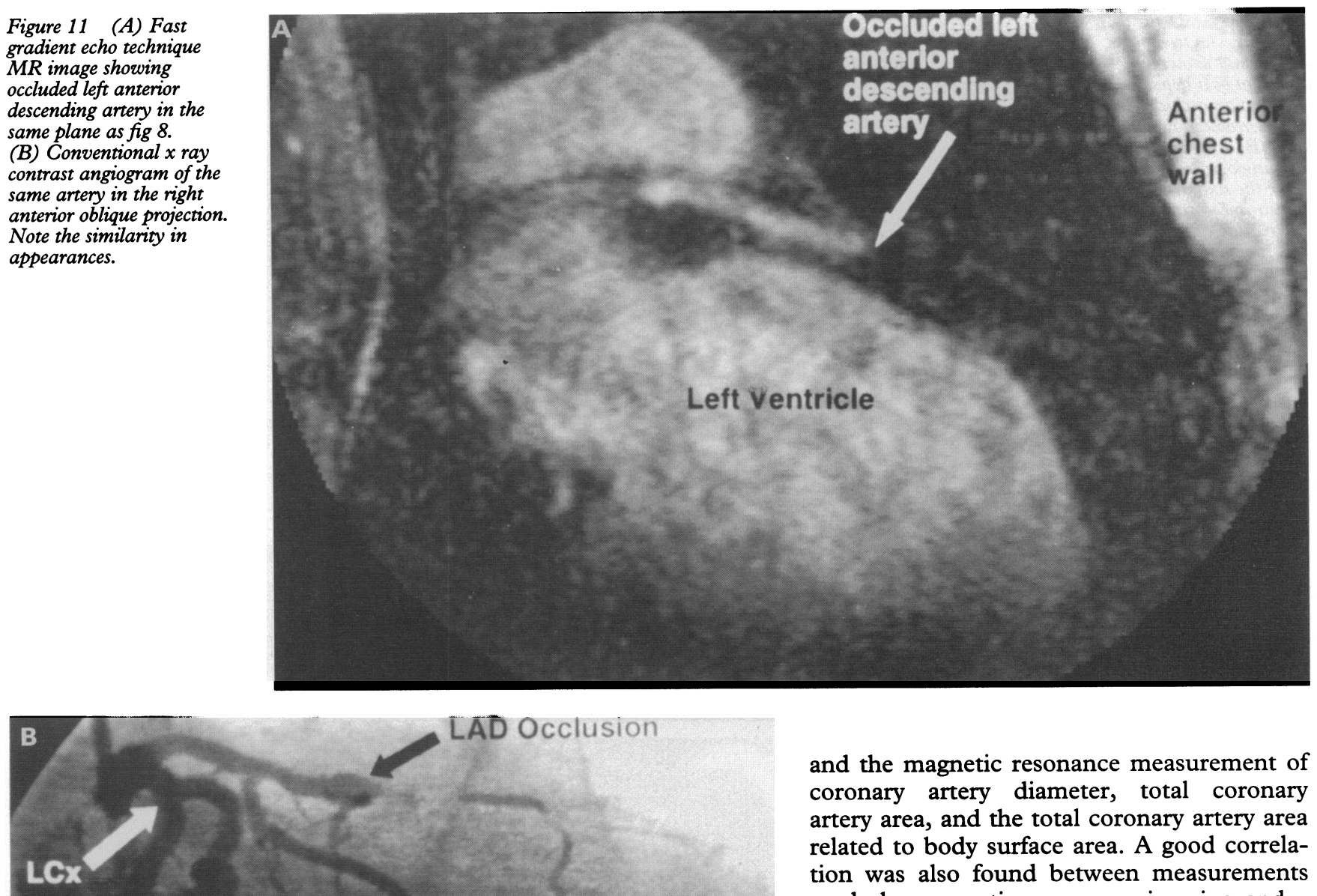

Right anterior oblique projection

section of the arteries. Suppression of signal from fat is also important. First, the artery becomes clearly identifiable, standing out from the surrounding fat and the adjacent myocardium and blood pools and second, suppression of the fat signal reduces the artefact seen at tissue interfaces, allowing a more accurate assessment of lumen size.

\section{RESULTS OF THIS STUDY}

This study demonstrates that magnetic resonance coronary angiography during breathholding is feasible, and its further development promises considerable advantages. This confirms the findings of previous reports using gradient echo imaging ${ }^{13} 14$ There was a good correlation between reference values and the magnetic resonance measurement of coronary artery diameter, total coronary artery area, and the total coronary artery area related to body surface area. A good correlation was also found between measurements made by magnetic resonance imaging and $x$ ray contrast coronary angiography in individual patients. This suggests that quantification of the technique could be possible with further development. The images show the good differentiation of artery from background that can be achieved with fat suppression, and the significant lengths of artery that can be imaged in oblique planes. The ability to image in oblique planes is crucial, and the absence of ionising radiation allows repeated studies to be performed should alignment be incorrect.

The patients with occlusion of a coronary artery had diagnostic images, and the insertion of vein grafts was clearly seen. Thus, little further development is required for the identification of major abnormalities of the coronary arteries and vein grafts.

DETECTION OF OCCLUSION AND STENOSIS BY RAPID GRADIENT ECHO MAGNETIC RESONANCE ANGIOGRAPHY

The segmented gradient echo technique shows blood as a high signal unless flow velocity is reduced or there is turbulence. Therefore, it may become possible to assess stenosis in the major vessels by signal loss, and a recent study has shown promising results. ${ }^{32}$ Experience in peripheral vessels, however, has suggested that turbulence leads to overestimation of the severity of the stenosis. $^{33}$

Stenosis may also be detected by cine magnetic resonance velocity mapping. ${ }^{34}$ Clinical results in native coronary arteries ${ }^{35-37}$ and bypass grafts ${ }^{18}$ have been achieved (fig 1). Haemodynamically significant obstructions 
Figure 12 (A) Fast gradient echo technique $M R$ image showing insertion of a bypass graft distal to an occluded lefi anterior descending artery and $(B)$ conventional $x$ ray angiogram of the graft. Note the similarity of appearances and the bifurcation of the left anterior descending artery shortly after the graft insertion.
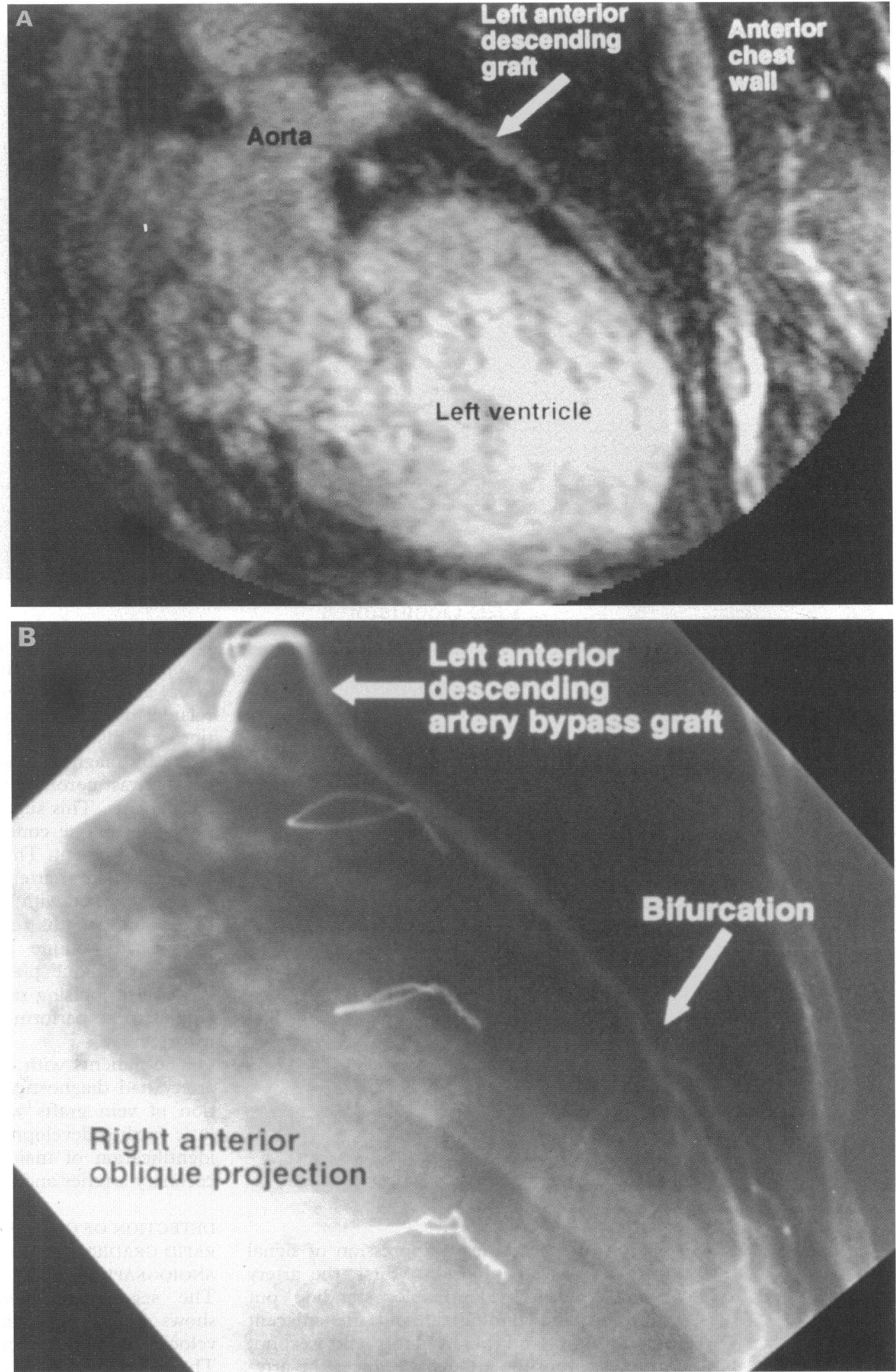

cause an increase in blood flow velocity which can be used to quantify their severity. ${ }^{38}$ Velocity mapping may reduce the interobserver variability that complicates $x$ ray contrast angiography..$^{39} 40$

PROBLEMS WITH THE PRESENT TECHNIQUE

Breath-holding for 16 cardiac cycles may be a problem for those with respiratory disease or heart failure. In addition the depth of inspiration may vary with each image, leading to misregistration of contiguous slices, which causes difficulties with interpretation and computer processing. ${ }^{41}$ Another problem is the shimming of the magnetic field for the fat suppression which may be difficult. The resolution of the images also needs to be improved if smaller arteries are to be studied. 
Figure 13 Fast gradient echo technique MR images of two vein grafts from their origin in the upper aorta. The native right coronary artery $(R C A)$ is occluded, and the graft can be seen descending to its distal insertion point. The left circumflex (LCX) graft can also be seen passing above the pulmonary artery $(P A)$.

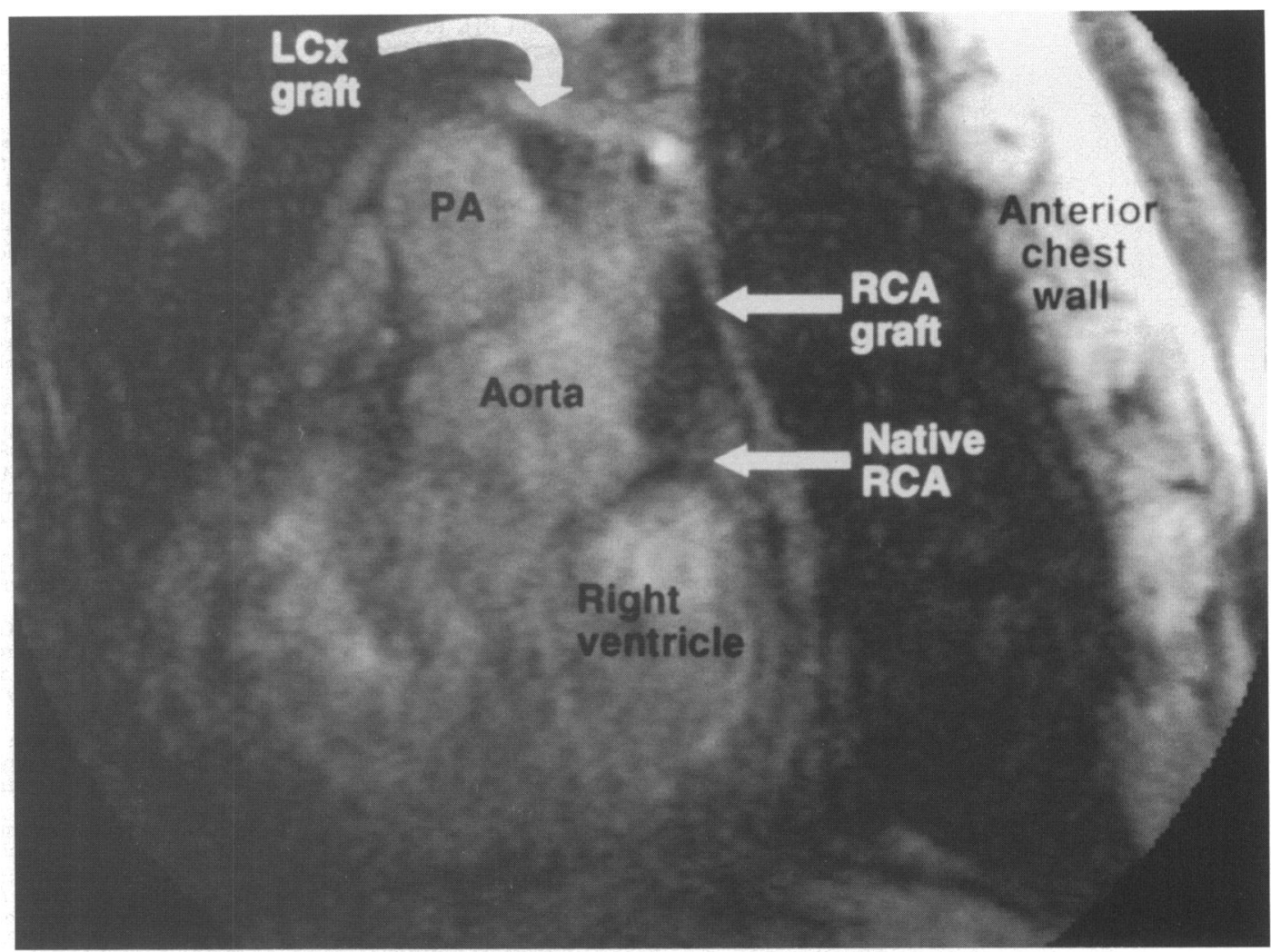

Dysrhythmia during the acquisition produces artefact, thus frequent extrasystoles are a problem, though reasonable images can be obtained in controlled atrial fibrillation. Finally, claustrophobia is a problem for a few patients.

\section{POSSIBLE FUTURE MAGNETIC RESONANCE DEVELOPMENTS}

Echo-planar imaging is a faster and more efficient technique than gradient echo imaging and can be applied to the coronary arteries. Because of its short data collection period (as low as $20 \mathrm{~ms}$ ), multiple planes can be acquired in a single breath-hold. While echoplanar imaging of the coronary arteries with rectilinear data collection has been achieved, ${ }^{30}$ a spiral k-space trajectory may also be used. Early results with an interleaved technique are promising, ${ }^{42}$ and further development is likely. In addition, sophisticated image processing techniques may improve the image quality. These techniques include computer generated projection views, ${ }^{41}$ three dimensional reconstructions, ${ }^{43}$ vessel tracking, ${ }^{44}$ and image enhancement. ${ }^{45} \mathrm{~A}$ further possibility is the development of chemical shift imaging of the arterial wall to permit measurement of lipid concentration in a stenosis. ${ }^{46}$ The knowledge of the lipid status of plaques has important prognostic and therapeutic implications, but improved resolution would be required for such imaging of the coronary arteries.

POSSIBLE ROLE OF MAGNETIC RESONANCE CORONARY ANGIOGRAPHY

Magnetic resonance imaging of the coronary arteries is at too early a stage to predict its future role. If it is assumed that further improvements in image quality can be made, then it may be useful for screening the major epicardial vessels for significant disease. Because of its safety, it could be used in younger age groups and those with contraindications to conventional angiography. In addition, repeated studies may be performed that would allow patients to be followed up regularly after intervention. It could therefore contribute to our knowledge of the natural history of the disease. Together with the proven ability of magnetic resonance to assess cardiac anatomy, perfusion and metabolism, it could lead to a comprehensive assessment of the cardiovascular system by magnetic resonance.

This study was funded in part by CORDA (The Coronary This study was funded in part by CORDA (The Coronary Foundation. We thank Dr JM Walker for permission to study his patients.

1 Kennedy JW, Baxley WA, Bunnel IL, et al. Mortality related to cardiac catheterisation and angiography. Cathet Cardiovasc Diagn 1982;8:323-40.

2 Davis K, Kennedy JW, Kemp HG, Judkins MP, Gosselin AJ, Killip T. Complications of coronary arteriography from the collaborative study of coronary artery surgery (CASS). Circulation 1979;59:1105-12.

3 Fram EK, Heiserman JE. Carotid and vertebral arteries. In: Potchen EJ, Haacke EM, Siebert JE, Gottschalk A eds. Magnetic resonance angiography, concepts and applications. St Louis: Mosby, 1993;498-518.

4 Kent KC, Edelman RR, Kim DD, Steinman TI, Porter DH, Skillman JJ. Magnetic resonance imaging: A reliable test for the evaluation of proximal atherosclerotic enal arterial stenosis. 7 Vasc Surg 1991;13:311-8.

5 Owens RS, Carpenter JP, Baum RA, Perloff LJ, Cope C. Magnetic resonance imaging of angiographically occult runoff vessels in peripheral arterial occlusive disease. $N$

6 Underwood SR. Imaging of acquired heart disease. In: Underwood SR, Firmin DN, eds. Magnetic resonance of the cardiovascular system. London: Blackwell, 1991; 41-67.

7 Underwood SR. Magnetic resonance imaging of the cardiovascular system. In: Sobel BE, Julian DG, Hugenholtz PG, eds. Perspectives in cardiology, 1988. London: Current Medical Literature, 1988;344-59. Engl f Med 1992;326:1577-81. 
8 Underwood SR, Firmin DN, Klipstein RH, Rees RSO, Longmore DB. Magnetic resonance velocity mapping: clinical applications of a new technique. Br Heart 1987;57:404-12.

9 White RD, Caputo GR, Mark AS, Modin GW, Higgins CB. Coronary artery bypass graft patency: Noninvasive evaluation with $M R$ imaging. Radiology 1987;164: 681-6.

10 Stehling MJ, Howseman AM, Ordidge RJ, et al. Whole body echo-planar MR imaging at 0.5T. Radiolog body echo-planar

11 Frahm J, Merboldt KD, Bruhn H, Gyngell ML, Hänicke W, Chien D. 0.3 second FLASH imaging of the human heart. Magn Reson Med 1990;13:150-7.

12 Riederer SJ, Tasciyan T, Farzaneh F, Lee JN, Wright RC, Herkfens RJ. MR fluoroscopy: Technical feasibility. Magn Reson Med 1988;8:1-15.

13 Edelman RR, Manning WJ, Burstein D, Paulin S. Coronary arteries: Breath-hold MR angiography. Radiology 1991;181:641-3.

14 Manning WJ, Li W, Boyle NG, Edelman RR. Fat-suppressed breath-hold magnetic resonance coronary angiography. Circulation 1993;87:94-104.

15 Bland JM, Altman DG. Statistical method for assessing agreement between two methods of clinical measureagreement between two metho

16 Dodge JT, Brown BG, Bolson EL, Dodge HT. Lumen diameter of normal coronary arteries. Influence of age, sex, anatomic variation, and left ventricular hypertroph or dilatation. Circulation 1992;86:232-46.

17 Abramson DI, Dobrin PB. Blood vessels and lymphatics in organ systems. Orlando: Academic Press, 1984; 320.

18 MacAlpin RN, Abbasi AS, Grollman JH, Eber L. Human coronary artery size during life. A cinearteriographic study. Radiology 1973;108:567-76.

19 Forssman W. Die Sondierung des rechten Herzens. Berl Klin Wochenschr 1929;8:2085-7.

20 Dotter CT, Frische LH. Visualisation of the coronary circulation by occlusion aortography: A practical method. Radiology 1958;71:502-23.

21 Sones FM. Acquired heart disease: Symposium on present and future of cineangiocardiography. $\operatorname{Am} \mathcal{f}$ Cardiol 1959;3:710.

22 Sones FM, Shirley EK. Cine coronary arteriography. Med Concepts Cardiovasc Dis 1962;31:735-8.

23 Judkins MP. Selective coronary arteriography. A percutaneous transfemoral technic. Radiology 1967;89:815-24.

24 Yoshida K, Yoshikawa J, Hozumi T, et al. Detection of left main coronary artery stenosis by transoesophageal color Doppler and two-dimensional echocardiography. Circulation 1990;81:1271-6.

25 Janowitz WR, Agatson AS, Viamonte M. Comparison of serial quantitative evaluation of calcified coronary artery plaque by ultrafast computed tomography in persons with and without obstructive coronary artery disease. with and without obstructive

26 Steiner RE, Bydder GM, Selwyn A, et al. Nuclear magnetic resonance imaging of the heart. Current status and future prospects. Br Heart $\mathcal{F} 1983 ; 50: 202-8$.

27 Alfidi RJ, Haaga JR, El-Yousef SJ, et al. Preliminary experimental results in humans and animals with superconducting, whole body, nuclear magnetic resonance scanner. Radiology 1982;143:175-81.

28 Paulin S, von Schulthess GK, Fossel E, Krayenbuehl HP. MR imaging of the aortic root and proximal coronary arteries. Am $\mathcal{F}$ Roentgenol 1987;148:665-70.

29 Dumoulin CL, Souza SP, Darrow RD, Adams WJ. A method of coronary MR angiography. $\mathcal{F}$ Comput Assist Tomogr 1991;15:705-10.

30 Stehling M, Howseman A, Chapman B, et al. Real-time NMR imaging of coronary vessels. Lancet 1987;ii: 964-5

31 Wang SJ, Hu BS, Macovski A, Nishimura DG. Coronary angiography using fast selective inversion recovery. Magn Reson Med 1991;16:417-23.

32 Manning WJ, Li W, Edelman RR. A preliminary report comparing magnetic resonance coronary angiography 328:828-32.

33 Yucel EK, Steinberg FL. Lower extremity and renal angiography. In: Potchen EJ, Haacke EM, Siebert JE, Gottschalk A, eds. Magnetic resonance angiography, concepts and applications. St Louis: Mosby 1993;597-606.

34 Bryant DJ, Payne JA, Firmin DN, Longmore DB. Measurement of flow with NMR imaging using a gradient pulse and phase difference technique. $\mathcal{f}$ Comput Assist Tomogr 1984;8:588-93.

35 Rees S, Firmin D, Mohiaddin R, Underwood R, Longmore $\mathrm{D}$. Application of flow measurements by magnetic resonance to congenital heart disease. $A m \mathcal{F}$ Cardiol 1989;64:953-6.

36 Edelman RR, Manning WJ. Flow quantification in human coronary arteries [abstr] $f$ Magn Reson Imag 1992; Coronary

37 Keegan J, Firmin DN, Gatehouse PD, Longmore DB. Velocity mapping in coronary arteries: Phantom studies and preliminary in-vivo results [abstr]. Proceedings of the 10th European Society of Magnetic Resonance in Medicine and Biology 1993;272.

38 Mohiaddin RH, Sampson C, Firmin DN, Longmore DB. Magnetic resonance morphological, chemical shift and flow imaging in peripheral vascular disease. Eur 7 Vasc Surg 1991;5:383-96.

39 Zir LM, Miller SW, Dinsmore RE, Gilbert JP, Harthorne JW. Interobserver variability in coronary angiography. Circulation 1976;53:627-32.

40 Kleiman NS, Rodriguez AR, Raizner AE. Interobserver variability in grading of coronary arterial narrowings using the American College of Cardiology/American Heart Association grading criteria. Am $\mathcal{f}$ Cardiol 1992; 69:413-5.

41 Siebert JE, Rosenbaum TL. Image presentation and postprocessing. In: Potchen EJ, Haacke EM, Siebert JE, Gottschalk A, eds. Magnetic resonance angiography, concepts and applications. St Louis: Mosby, 1993; 220-45.

42 Meyer CH, Hu BS, Nishimura DG, Macovski A. Fast spiral coronary artery imaging. Magn Reson Med 1992; 28:202-13.

$43 \mathrm{Li} \mathrm{D}$, Paschal CB, Haacke EM, Adler LP. Coronary arteries: Three dimensional MR imaging with fat saturation and magnetisation transfer contrast. Radiology 1993; 187:401-6.

44 Mohiaddin RH, Yang GZ, Burger P, Firmin DN, Longmore DB. Automatic enhancement, animation, and segmentation of flow in peripheral arteries from MR phase-shift velocity mapping. $\mathcal{F}$ Comput Assist Tomogr 1992;16:176-81.

45 Yang GZ, Burger $P$. The application of relaxation labelling process to NMR flow image analysis. Proceedings of the fourth International Conference on Image Processing and Its Applications. London: IEE, 1992;45-8.

46 Mohiaddin RH, Firmin DN, Underwood SR, et al. Chemical shift magnetic resonance imaging of human atheroma. Br Heart f 1989;62:81-9. 